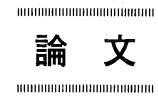

\title{
石炭粒子の急速熱分解で生成するタールの 化学的構造に及ぼす温度の影響
}

\author{
(キーワード 急速熱分解, タール, 構造パラメー夕, 分子量, 二次分解) \\ -1989.11 .30 受理
}

九州大学 林 潤一郎, 安藤 亮, 前園 利樹 草壁 克己, 諸岡 成治

\section{1. 緒 言}

石炭の熱分解反応は液化, ガス化, 燃焼等の石炭変 換プロセスの中核をなすものである。従って，その反 応機構を解明することは重要な意味を持つ。微粉砕し た石炭粒子を急速に短時間で昇温して熱分解を行う石 炭の急速熱分解（Flash coal pyrolysis）では液状成分 が高い収率で得られ, また, 生成タールの 2 次分解が 少ないことから石炭の熱分解機構を明らかにする重要 な研究手段になっている1)。

従来の急速熱分解反応モデルではメタプラスト理 論2 2) に) に代表されるように, 熱分解生成物をいくつ かに lumping し，揮発分収率等を予測するものが一般 的であった。しかし, 石炭高分子の構造とその变化に 対してのモデル化を行い，揮発分収率或は溶媒可溶成 分を予測しようとする試みが Niksa ${ }^{5)}$ や Solomon ら ${ }^{6)}$ によってなされている。また，芳香族環を主体とした 合成ポリマーを石炭モデル物質として熱分解で生成す る揮発成分の分子量分布を測定した研究例 ${ }^{7}$ もある。

石炭は多置換された多核芳香族環がアルキル鎖, エーテル結合によりつながれた有機高分子体と考えら れる。そこで, 高分子としての石炭の熱分解反応の機 構を明らかにすること, 更には石炭の分子構造 (基本 構造㧍よび分子量）に基づいて熱分解反応のモデル化 を行うことは重要である。

本研究は自由落下型熱分解反応器を用いて 2 種の石 炭の熱分解を行い, 生成するガス, タールの生成物分 布㧍よび生成量を測定した。生成物のうち, 特に夕ー ルの構造变化に着目し, 平均的化学構造を ${ }^{1} \mathrm{H}$ NMR に

工学部応用化学科 福岡市東区箱崎 6-10-1
より分析し, 平均分子量並びに分子量分布をVPO 法 拉よび GPC 法により求め, 夕ールの単位構造が熱分 解温度に対してどのように変化し, それが分子量にど のように反映されるかを調べた。また，揮発せずに石 炭粒子内に残留しているタールの構造変化についても 検討した。

\section{2. 実 験}

\section{1 試料}

本実験では粘結炭である Pittston 炭と非粘結炭であ る Optimum 炭（いずれも歴青炭）を使用した。石炭 の分析值を Table 1 に示す。石炭は粉砕して分級し 粒径105-210 $\mu \mathrm{m}$ のものを用いた。石炭粒子は事前に 真空下, $110^{\circ} \mathrm{C}$ で 6 時間乾燥した。

\section{2 熱分解実験装置と方法}

Fig. 1 に実験装置の概略を示す。反応管は内径 $38 \mathrm{~mm}$, 長さ $800 \mathrm{~mm}$ の透明石英管であり, 電気炉によ り加熱した。反応管中央部に約 $600 \mathrm{~mm}$ の等温部があ り，その上下はなるべく低温となるように電気炉を設 計した。反応器が所定の温度に達した後, 石炭粒子を 反応器上部のノズル (内径 $3 \mathrm{~mm})$ から $(0.20 \pm 0.02)$ g-coal $\cdot \min ^{-1}$ の供給速度で同伴窒素ガス（流量 : $\left.100 \mathrm{ml} \cdot \min ^{-1}\right)$ とともに落下させた。反応管には $2000 \mathrm{ml} \cdot \mathrm{min}^{-1}$ の流量で窒素ガスを流通させた。熱分 解生成物のうち, チャーは反応器下部のコレクターで, タールはドライアイスコールドトラップで捕集し, 生 成ガスは同伴窒素ガスと共に全量サンプリングバッグ に捕集した。トラップしたタールは THF あるいはク ロロホルムに溶解して回収した後, 溶媒を留去した。 熱分解時の石炭粒子の密度, 粒径を一定とし, 反応 
Table 1 Analytical data of coal samples

\begin{tabular}{|c|c|c|c|c|c|c|}
\hline \multirow[t]{2}{*}{ Coal } & $\mathrm{C}$ & $\mathrm{H}$ & $\mathrm{N}$ & $\mathrm{O}($ diff. $)$ & $S$ & Ash \\
\hline & \multicolumn{5}{|c|}{$[\mathrm{wt} \%, \mathrm{daf}]$} & [wt\%] \\
\hline Pittston & 84.3 & 5.48 & 1.59 & 7.79 & 0.84 & 5.71 \\
\hline Optimum & 82.2 & 5.21 & 1.98 & 10.01 & 0.60 & 10.21 \\
\hline
\end{tabular}

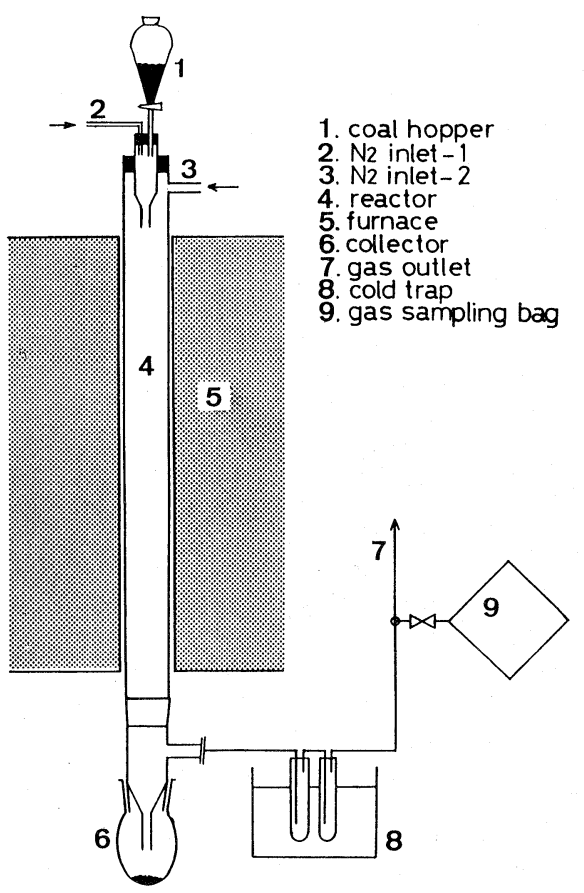

Fig. 1 The schematic diagram of free-fall reactor

熱を小さいと仮定して Solomon $ら^{8)}$ の計算方法に従 い，石炭粒子の反応時間おょび昇温速度を計算したと ころ，それぞれ0.6-0.7s および1000-3000K・融と なった。

\section{3 生成物の分析}

水素は TCD 付 GC で, C1-C3 の炭化水素は FID 付 $\mathrm{GC}$ でそれぞれ分析した。 $\mathrm{CO}$ と $\mathrm{CO}_{2}$ は分離カラムを 通した後メタン化して FID 付 GCで定量した。原炭 およびチャーはピリジンでソックスレー抽出し，ピリ ジン可溶分（PS成分）とピリジン不溶分（PI 成分） に分けた。

タールおよびPS 成分の分子量分布は移動相として THF を用い, 可視紫外吸光光度計および示差屈折計 を検出器とした GPCで測定した。分子量較正曲線は 標準物質にポリスチレンを用いて作成した。数平均分 子量は蒸気圧浸透法（VPO）により決定した。ター ルおよびPS成分中のクロロホルム可溶分について ${ }^{1} \mathrm{H}$ NMR 分析を行った。

\section{3. 結果と考察}

\section{1 熱分解生成物分布}

Fig. 2 に熱分解生成物分布の温度依存性を示す。 Pittston 炭のタール収率は800K から急増し, 900K 付 近で最大值をとり，温度を更に高くすると次第に減少 した。Optimum 炭の場合も同様な傾向を示し, 夕ー
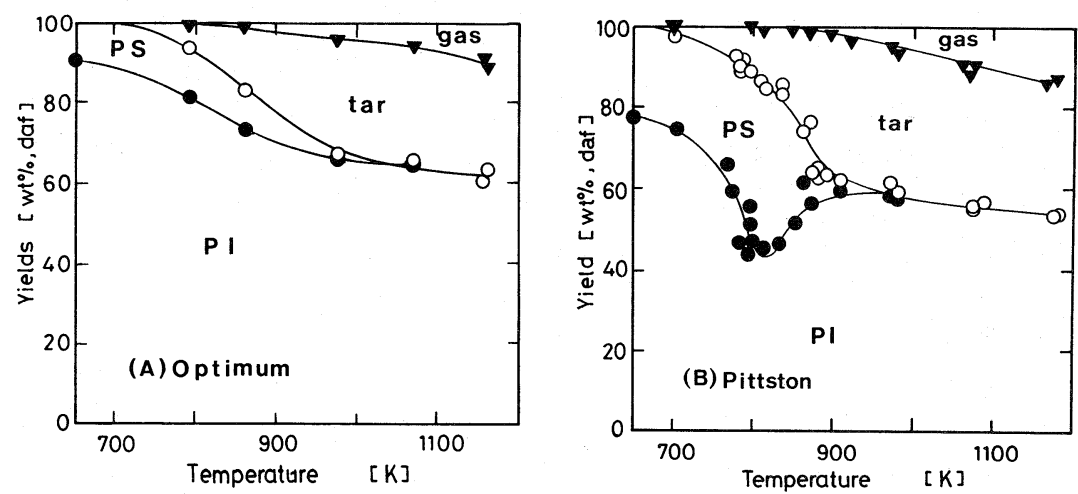

(A), Optimum coal ; (B), Pittston coal

Fig. 2 Product distribution as a function of peak temperature 

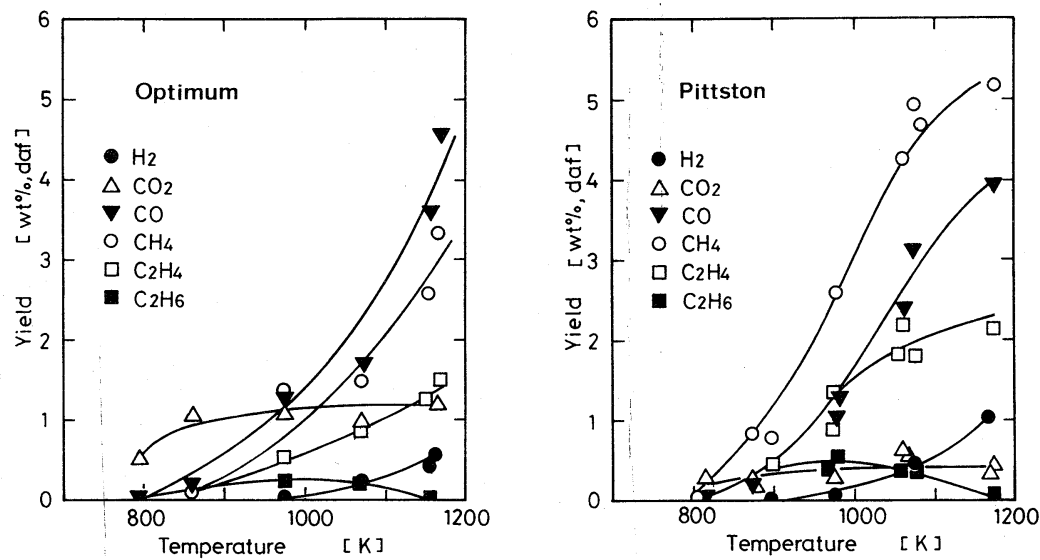

Fig. 3 Gas yields from Optimum coal and Pittston coal

ル収率は950K 付近で最大となった。PS 成分収率は 2 炭共に $800 \mathrm{~K}$ 付近で最大となるが, Pittston 炭のPS 成 分収率は $40 \mathrm{wt} \%, \mathrm{daf}$ （原炭の約 2 倍）に達するのに対 して，Optimum 炭では $12 \mathrm{wt} \%$, daf にすぎず，原炭の PS 収率と殆ど変化がない。これは, Dorman $ら^{9)} に よ$ る低速昇温下での熱分解の結果と同様に, Pittston 炭 が粘結炭であるのに対して Optimum 炭が非粘結炭で あることに対応している。ガス収率はいずれも $900 \mathrm{~K}$ 以上で増大した。各ガス成分の温度依存性を Fig. 3 に示す。Pittston 炭はOptimum 炭に比べて $\mathrm{H}_{2}, \mathrm{CH}_{4}$, $\mathrm{C}_{2} \mathrm{H}_{6}$ 等の水素を含むガス生成量が多い。

\section{2 各生成物のキャラクタリゼーション}

\section{2 .1 生成物の $\mathrm{H} / \mathrm{C}$ 比と水素収支}

Fig. 4 に各生成物の $\mathrm{H} / \mathrm{C}$ 比の温度依存性を示す。 原炭の $\mathrm{H} / \mathrm{C}$ 比は 0.80 であることから, 夕ールは石炭 あるいはチャーに比べてかなり水素に富んだ平均構造 を持っているといえる ${ }^{9) 10)}$ 。一方, PS 成分の $\mathrm{H} / \mathrm{C}$ 比 は原炭とほほ等しく, 温度依存性が殆どみられなかっ た。

Fig. 5 に Pittston 炭の水素収支を熱分解温度に対し てプロットした。チャー，タール，ガスそれぞれに含 まれる水素と収率から求めた水素量の和は，原炭中の 水素とほぼバランスした。タールの生成がほぼ終了し たと考えられる900K より低温側におけるチャー中の 水素の減少は水素に富む夕ールの放出によるものであ る。また，900Kより高温側での水素の減少はガスの 脱離によるものであり，メタンおよび水素の寄与が特 に大きい。タールに含まれる水素量は900Kにおいて 最大 $2.4 \mathrm{wt} \%$, daf となるが, さらに高温では減少し, 1200K では $1.6 \mathrm{wt} \%$, daf となる。この減少は夕ール中

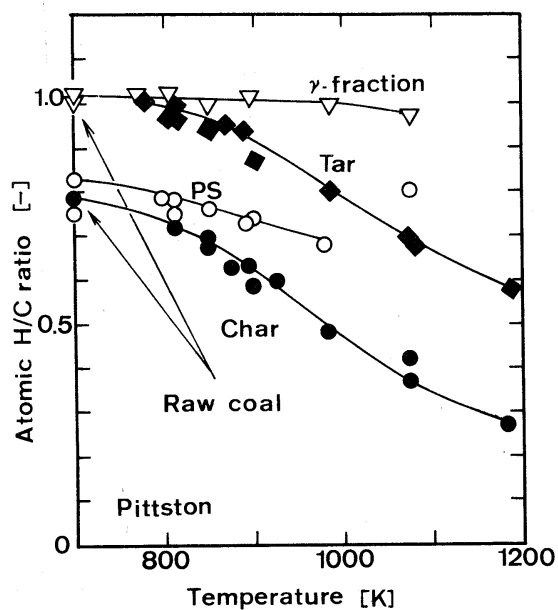

Fig. $4 \mathrm{H} / \mathrm{C}$ atomic ratio of pyrolysis products from Pittston coal

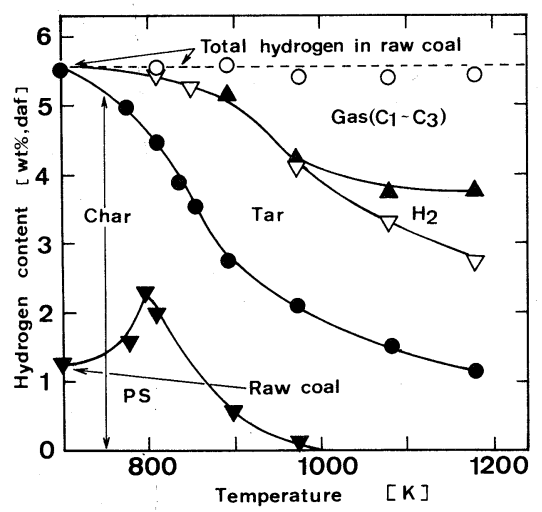

Fig. 5 Effect of temperature on hydrogen fraction in products from Pittston coal 
の水素のガスへの移行，すなわち，タールの二次分解 によるものであろう。

\section{2 .2 タールの構造パラメータの変化}

Fig. 4 に示した熱分解温度の上昇にともなうタール の $\mathrm{H} / \mathrm{C}$ 比の低下は，タールの芳香族化を反映してい る。そこでタールの芳香族化の機構を明らかにするた めに ${ }^{1} \mathrm{H} \mathrm{NMR}$ 分析を行い, タールの構造変化を調べた。 なお, 構造パラメータの導出は Brown-Ladner の式 ${ }^{11)}$ に従った。

Fig. 6 にタール中の水素分布を示す。 $\mathrm{H}_{\mathrm{ar}}$ は熱分解 温度とともに単調に増大している。脂肪族水素のうち $\mathrm{H}_{\beta}, \mathrm{H}_{\gamma}$ は800K からすでに減少しているが, $\mathrm{H}_{\alpha}$ は

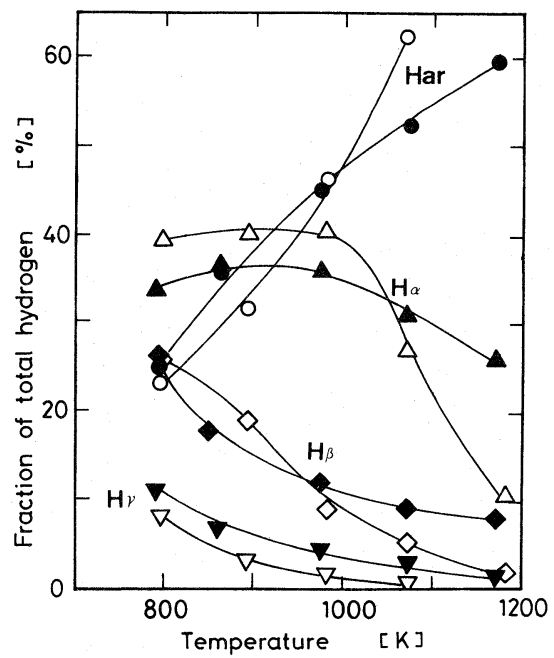

Fig. 6 Hydrogen fraction in Optimum tar $\nabla, \nabla)$ and Pittston $\operatorname{tar}(\bigcirc, \Delta, \diamond, \nabla)$
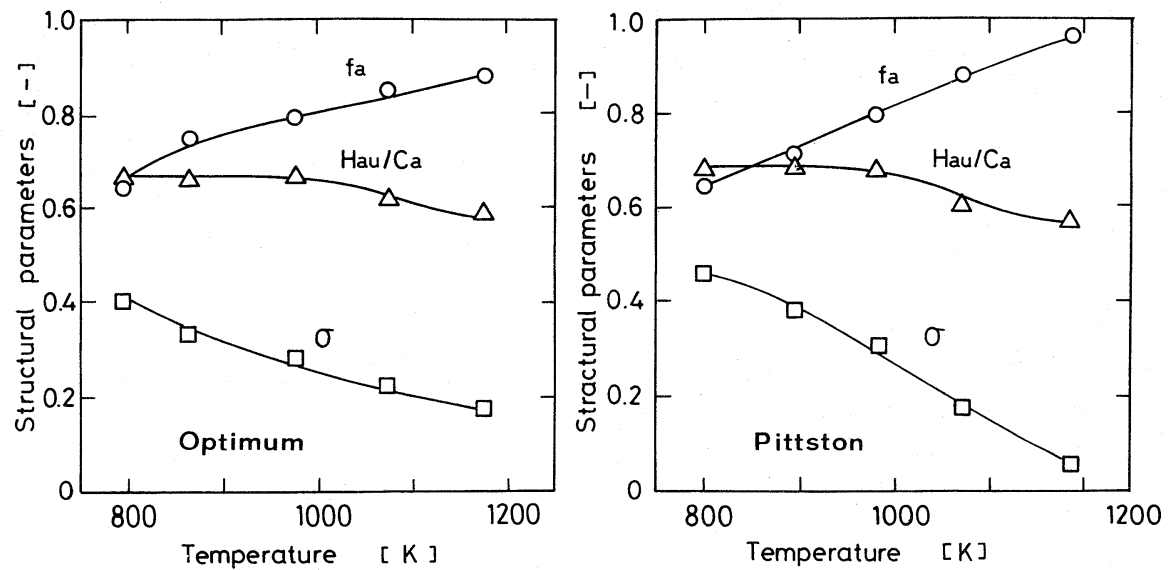

1000K まで全く減少の傾向を示さず， $\alpha$ 位の炭素は熱 的に非常に安定であることを示している12)13)。Fig. 7 にタールの構造パラメータの変化を示す。 $\mathrm{f}_{\mathrm{a}}$ は温度 と共に単調に上昇している。芳香族環の外周炭素が置 換された割合 $(\sigma)$ は熱分解温度の上昇に従って減少 しており，置換基の脱離が平均鎖長の減少とともに進 行していることがわかる。また，同図中に芳香族炭素 に対する外周炭素の割合を示す。この值は熱分解温度 が973K 以下では Pittston 炭, Optimum 炭ともに 0.65-0.70前後で一定値となる。この温度領域では タールを構成する芳香族環の縮合環数は変化しないの で，タールの芳香族性が温度と共に増加するのは芳香

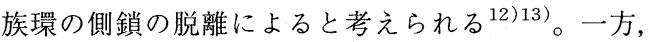
熱分解温度が973K を越えると縮合環数が増加してい る。一般に，芳香族環の縮合反応は芳香族水素，ある いは $\alpha$-メチル基等の脱離を伴う。前述したように, $\alpha$ 位の炭素は $973 \mathrm{~K}$ 以上で減少しており， $\alpha$ 炭素の分 解と芳香族環の縮合が同時に進行していると考えられ る。

\section{2 .3 タールの分子量の変化}

Fig. 8 に Pittston 炭タールの分子量分布を示す。図 中に表された分布曲線は重量分率を分子量で微分した ものである。分布のピークは $\mathrm{MW}=300-500$ にあり， また，MW>1000のフラクションは $10 \%$ 程度と少ない。 Table 2 に, Pittston 炭について GPC 法から求めた $\mathrm{M}_{\mathrm{n}}, \mathrm{M}_{\mathrm{w}}$ および VPO 法から求めた $\mathrm{M}_{\mathrm{n}}$ を示す。GPC 法で得た分子量はポリスチレン換算であるが，VPO 法で求めた值とほぼ一致している。平均分子量は 800-900K の範囲では殆ど変化がなかったが，900K 以 上では急激に減少した。Optimum 炭のタールも分布

Fig. 7 Structural parameters of Optimum tar and Pittston tars 


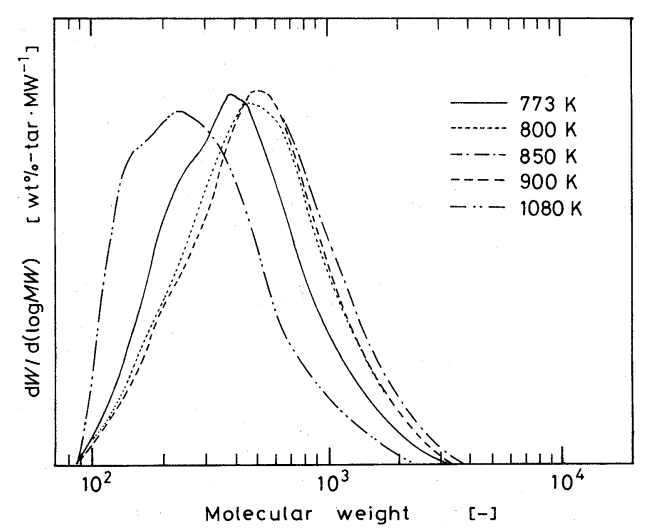

Fig. 8 Molecular weight distributions of Pittston tar

のピークは $\mathrm{MW}=300-500$ にあり, 温度依存性も Pittston 炭と同様であった。973K 以下で得られた タールの Hau/Ca 值 (0.65-0.70)から,これらが4環 (C=18) の縮合環を仮定し，これに外周基とへテロ 原子を加えて単位構造の分子量を計算すると, $800 \mathrm{~K}$ と $900 \mathrm{~K}$ での值はそれぞれ380、350となり，VPO，ある いは GPCで求めた平均分子量によく一致する。これ より, タールの数平均重合度はほぼ1（モノマー）で あることがわかる。1073K 以上で得られたタールにつ いても, $\mathrm{H}_{\mathrm{au}} / \mathrm{C}_{\mathrm{a}}$ 值が0.57-0.60となることから 5 環 ( $\mathrm{C}=19)$ の芳香族環を仮定すると, 単位構造の分子 量は 250 程度となり実測值とほぼ一致した。タールの 数平均分子量の減少は, 芳香族縮合環の外周基が脱離 するために起こり, 重合度の低下による影響は小さい。 本実験で得られたタール構造の熱分解温度依存性は, 流動床を用いて Liddel 炭の急速熱分解を行った Collin $ら^{11)}$ の実験結果と一致している。一方, Unger $ら^{9) 14)}$ は夕ールの二次分解が無視できるメッシュ加熱 法 ${ }^{15) 16)}$ で石炭の急速熱分解を行い, タールの分子量 分布を調べたが, タールの分子量分布は殆ど温度依存 性を示していない。

\section{2 .4 粒子内の夕ール}

本実験では熱分解温度が低いほどタールの二次分解 の影響は小さくなり，800K 付近で生成したタールは 石炭粒子から放出された瞬間の状態とほぼ同じ構造を 有すると予想される。低温下の熱分解では低分子の生 成速度に比べて生成したタールが粒子外へ拡散される 速度が遅くなるので，一部の夕一ルは粒子内に蓄積す る。これを粒子内タールであるとすれば，その構造は 二次分解を受ける前のタールのそれに等しいはずであ
Table 2 Average molecular weights of Pittston tar

\begin{tabular}{rccc}
\hline $\begin{array}{c}\text { Temp. } \\
{[\mathrm{K}]}\end{array}$ & $\mathrm{M}_{\mathrm{n}}(\mathrm{GPC})$ & $\mathrm{M}_{\mathrm{n}}(\mathrm{VPO})$ & $\mathrm{M}_{\mathrm{w}}(\mathrm{GPC})$ \\
\hline 773 & 330 & 320 & 510 \\
800 & 410 & 400 & 620 \\
850 & 410 & 390 & 650 \\
900 & 390 & 350 & 630 \\
930 & 330 & - & 550 \\
1080 & 230 & 250 & 360 \\
\hline
\end{tabular}

る。

Brown ${ }^{17}$ ) らは熱処理炭中の $\gamma$ 成分 (PS 成分中のク ロロホルム可溶分）量を調べているが， $\gamma$ 成分の H/ $\mathrm{C}$ 比, $\mathrm{M}_{\mathrm{n}}$ が本実験で得たタールの值と類似している ことから，本実験においても $\gamma$ 成分を抽出した。その 分子量分布を Fig.9 に示す。分布はタールと類似して いる。なお, H/C 比の温度依存性は非常に小さく, 収率は最大でも $6 \mathrm{wt} \%$, daf (800K) であった。Fig. 10 に $\gamma$ 成分の各種構造パラメータを示す。 $\gamma$ 成分の単位 構造は低温タールとほほ等しく， $\sigma$ の值は熱分解温度 に従って多少減少しているものの, 温度による構造変 化が非常に小さく，二次分解を受けないタールの分子 量分布は熱分解温度に依らないとする Unger $5^{9) 14)}$ の実験結果と一致する。従って $\gamma$ 成分を粒子内タール とすることは妥当であると考えられる。

メタプラスト理論をベースにした熱分解モデルに関 する最近の研究では, THF 抽出分 ${ }^{18)}$ ，あるいはPS成 分 ${ }^{19)}$ を粒子内のタール (メタプラスト) としている。 Fig. 11 にPS および $\gamma$ 成分の分子量分布を示す。PS 成分は H/C 比のみならず分子量分布もタールとは明

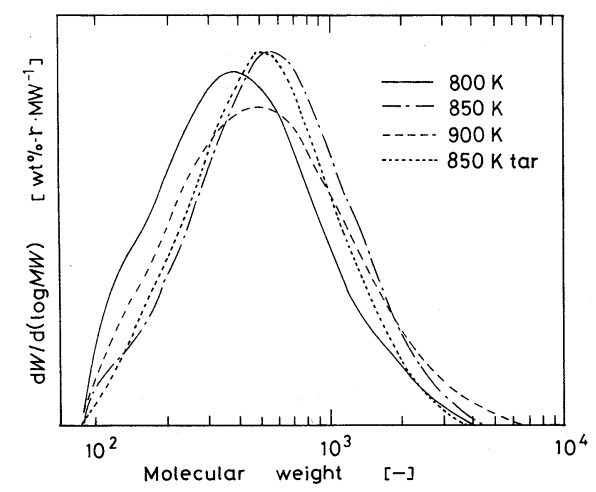

Fig. 9 Molecular weight distributions of $\gamma$ fraction in Pittston coal char 


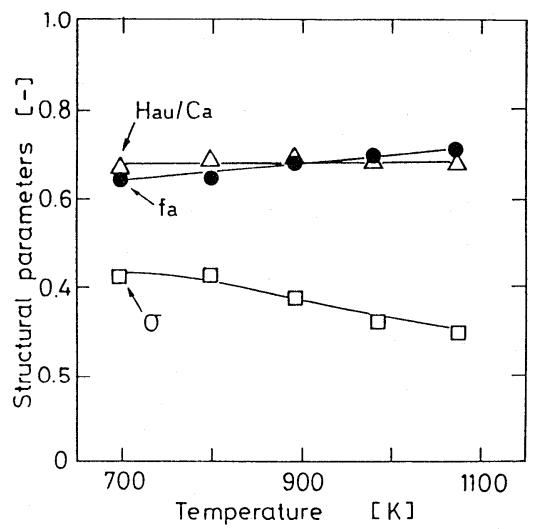

Fig. 10 Structural parameters of $\gamma$ fraction in Pittston coal char

らかに異なっており，これを粒子内タールとすること は不適当である。また，PS成分の約 $50 \%$ を占める $\mathrm{MW}<1000$ 以下のフラクションのうち $\gamma$ 成分に該当し ない成分も多く，粒子内の低分子がタールとなりうる かどうかは，分子量だけでなく単位構造もあわせて判 断する必要がある。

\section{4. 結 言}

Pittston 炭および Optimun 炭を落下型反応器で反応 温度を変えて急速熱分解し，生成物分布および夕ール の構造について以下の結果を得た。

(1) タールの芳香族化は芳香族環の側鎖の脱離によ るものであるが、熱分解温度が $973 \mathrm{~K}$ 以下では芳 香族環の縮合環数は変化しない。973K 以上では 縮合環数が増加する。

(2) 夕ールの数平均分子量は200-400程度であり、 ${ }^{1}$ H NMR から決定された最小構成単位の分子量と 良く一致した。

（3）熱分解チャー中の $\gamma$ 成分と二次分解を受けてい ないタールの構造パラメータ, 分子量は良く一致 した。

\section{(謝辞)}

本研究を行うに当たり有用なご助言をいただきまし た九州大学 谷口宏教授, 持田勲教授に謝意を表しま す。

\section{文献}

1 ）許維春, 富田影, 燃協誌，67, 14 (1988)

2 ) Fitzgerald, D., Fuel, 36, 389 (1957)

3 ) Van Krevelen, D. W., Coal, Elsevier Publishing Co., Amsterdam (1961)

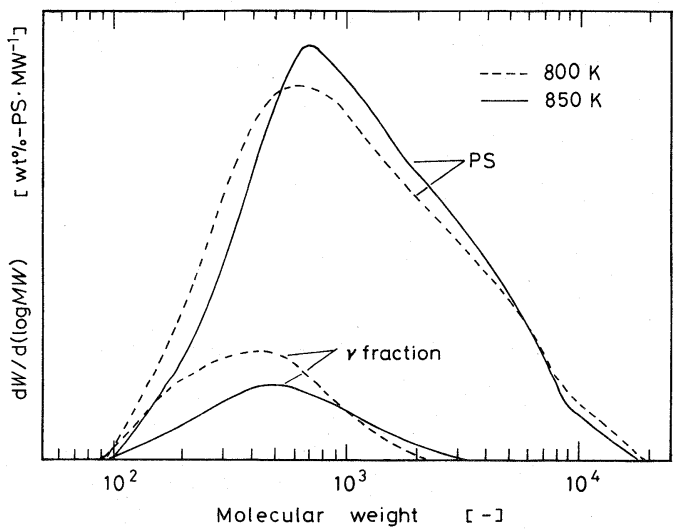

Fig. 11 Molecular weight of pyridine extract and $\gamma$ fraction in Pittston coal char

4 ) Fong, W. S., Peters, W. A. and Howard, J. B., Fuel, 65, 251 (1986)

5.) Niksa, S. and Kerstein, A.R., Fuel, 66, 1389 (1987)

6 ) Solomon, P. R., Hamblen, D. G., Carangelo, R. M., Serio, M. A. and Deshpande, G. V., ACS Div. of Fuel Chem. Preprints, 32, 83 (1987)

7 ) Squire, K. R., Solomon, P. R., Carangelo, R. M. and DiTaranto, M. B., Fuel, 65, 833 (1986)

8 ) Solomon, P. R., Serio, M. A., Calangero, R. M. and Markham, J. R., Fuel, 65, 182 (1986)

9 ) Suuberg, E. M., Unger, P. E. and Lilly, W. D., Fuel, 64, 956 (1984)

10) Miknis, F. P., Turner, T. F., Ennen, L, W. and Netzel, D. A., Fuel, 67, 1568 (1988)

11) Brown, J. K. and Ladner, W. R., Fuel, 39, 87 (1960)

12) Collin, P. J., Tyler, R. J. and Wilson, M. A., Fuel, 59, $479(1980)$

13）加我晴生，北野邦尋，武田詔平，燃協誌， 66, 224 (1987)

14) Unger, P. E. and Suuberg, E. M., Fuel, 63, 606 (1984)

15) Anthony, D. B., Howard, J. B., Hottel, H. C. and Meissner, H. P., Fuel, 55, 121 (1976)

16) Russel, W. B. and Saville, D, A., Ind. Eng. Chem. Fundam., 25, 536 (1986)

17) Brown, H. R. and Waters, P. L., Fuel, 44, 17 (1965)

18) Niksa, S., AIChE J., 34, 790 (1988) 
19) Oh, M. S., Peters, W. A. and Howard, J. B., AIChE

J., 35, 775 (1989)

\title{
Effect of Temperature on Chemical Structure of Flash Pyrolysis Tar
}

\author{
Jun-ichiro HAYASHI, Toshiki MAEZONO, Makoto ANDO, \\ Katsuki KUSAKABE and Shigeharu MOROOKA \\ (Department of Applied Chemistry, Kyushu University)
}

SYNOPSIS : - Flash pyrolysis of two bituminous coals (Pittston, Optimum) in a free fall reactor was studied at the temperature of 700-1200 K. The structure of tar was determined by ${ }^{1} \mathrm{H} \mathrm{NMR}$, and the number-average molecular weight and the molecular weight distribution were measured by means of VPO and GPC.

The tar yield reaches the maximum value at 900-950 $\mathrm{K}$ for both coals. The aromaticity increases monotonously with an increase in the pyrolysis temperature, which is due to the elimination of aliphatic peripheral groups occurring below $973 \mathrm{~K}$. At higher temperatures, the change in the structure unit is caused by the condensation of aromatic ring.

The calculated molecular weight of a structure unit agrees with the number-average molecular weight of tar obtained by VPO. This indicates the tar mainly consists of 1-2 structure units. The molecular weight distribution of tar is hardly dependent on the pyrolysis temperature in spite of the elimination of aliphatic groups below 900 $\mathrm{K}$. However, the distribution shifts toward the lower molecular weight range above $900 \mathrm{~K}$, which is properties of $\gamma$ fraction in char are very similar to those of the low temperature tar, and little structural change is observed in the range of $800-1100 \mathrm{~K}$.

\section{Key Words}

Flash coal pyrolysis, Tar, Structural parameters, Molecular weight, Secondary decomposition 